\title{
Nonlinearities and Robustness in Growth Regressions Jenny Minier*
}

Much economic growth research has been devoted to determining the explanatory variables that explain cross-country variation in growth rates. A frequently cited problem with this literature is that the number of potential growth regressors is vast, potentially exceeding the number of countries available for study. Thus, researchers are faced with the task of arbitrarily specifying which explanatory variables to include in their growth regressions, raising concerns about how confident we can be in their results. These concerns were magnified by the influential paper of Ross Levine and David Renelt (1992), in which they employ a variation of Edward E. Leamer's (1983) extreme bounds analysis to test the robustness of conventional growth regression coefficients to changes in the set of conditioning variables. They conclude that the results of this literature are extremely fragile, with the only robust determinants of growth being physical capital investment, initial income, and secondary school enrollment. In contrast, they demonstrate the fragility of a host of fiscal, monetary, and trade policy variables, as well as measures of political and economic stability and economic distortions.

There have been two main responses to their findings. The pessimistic response has been to conclude, given the lack of a reliable statistical relationship between conventional macroeconomic indicators and growth, that cross-country growth regressions cannot tell us anything about growth. The more optimistic response has been to argue that the extreme bounds analysis of Leamer (1983) is excessively stringent, requiring the coefficient estimate of interest to be statistically significant in all specifications. Thus, other researchers have proposed alternative, less stringent, approaches to robustness in the growth context (e.g., Xavier X. Sala-iMartin (1997) and Gernot Doppelhofer, Ronald I. Miller, and Sala-i-Martin (2004)). 
However, a third possible interpretation of the Levine and Renelt (1992, henceforth L-R) results is that the extreme sensitivity of the coefficient estimates is due to unreasonably strict assumptions about the form of the growth regression. In particular, L-R employ the common specification common that explanatory variables enter the growth regression linearly and independently. This reflects an ad hoc assumption that the marginal effect of a change in an explanatory variable is constant, both across different levels of the variable and across different economies. In fact, much of the empirical growth literature documents the existence of multiple growth regimes and parameter heterogeneity (see, among numerous others, Steven N. Durlauf and Paul A. Johnson (1995)). The apparent fragility of conventional growth regressions could reflect a rejection of the conventional assumptions of linearity and independence.

\section{Robustness Tests}

The traditional approach to economic growth regressions is to assume linearity and independence of the control variables and estimate an equation of the form:

$$
Y=\beta_{m} M+\boldsymbol{\beta}_{z}{ }^{\prime} \boldsymbol{Z}+u
$$

where $Y$ is per capita GDP growth, $M$ is the variable of interest, and $\boldsymbol{Z}$ is an arbitrarily chosen set of control variables. The obvious concern with this approach is that the choice of the set of control variables, $\boldsymbol{Z}$, can influence the estimate of $\beta_{m}$. To test the robustness of the coefficient estimates generated by such an approach, L-R adapt the "extreme bounds analysis” of Leamer (1983). L-R systematically vary the subset of $\boldsymbol{Z}$ variables included in the regressions, where the $\boldsymbol{Z}$ variables are chosen from a pool of variables commonly used as indicators of the fiscal, trade or monetary environment or as measures of economic or political instability, and always include the investment share of GDP, initial GDP per capita, initial secondary-school enrollment rate, 
and the average annual rate of population growth. ${ }^{1} \mathrm{~L}-\mathrm{R}$ estimate regressions adding all possible combinations of up to three additional control variables, and define the extreme upper (lower) bound as the highest (lowest) value of the estimate $\beta_{m}$ plus (minus) two standard deviations. A variable is considered "robust" if the estimate of $\beta_{m}$ remains statistically significant and of the same sign at the bounds. For complete details of the procedure, see Levine and Renelt (1992).

Their basic conclusion is that the results of cross-country regressions are highly sensitive to small changes in the conditioning set. The only variables found to be robustly correlated with per capita GDP growth come from the set of variables included in each regression: initial income, investment, and secondary school enrollment rate. Of more than 30 other variables common to the growth literature, they find that none is robustly correlated with growth. However, as in the traditional literature, L-R impose an assumption of linearity and independence on their specification, raising the question of whether the perceived fragility of such growth regressions reflects a rejection of these conventional assumptions. In the following sections, I allow for several simple types of nonlinearities in the L-R framework to see if the pessimistic conclusions that have been drawn from their work are specific to the linear case.

\section{Nonlinearities and Parameter Sensitivity}

In what follows, I repeat the L-R robustness procedure, allowing for three types of nonlinearities for each of the variables that they consider. ${ }^{2}$ To demonstrate the difference between their results and their procedure allowing for nonlinearities, I use the L-R data - two cross-sectional samples covering $1960-89$ or $1974-89$, depending on data availability. ${ }^{3}$

\section{II.A. Squared Terms}


One possibility is that the partial effect of a variable on per capita growth varies over different levels of the variable itself. For example, government expenditure on education may have a positive effect on growth, but with diminishing marginal returns. In that case, a linear specification could mask the positive correlation, since the slope of the parameter estimate tends toward zero as expenditure increases. Thus, I repeat the L-R procedure by including a squared term for the variable of interest in the regression specification:

$$
Y=\beta_{m} M+\beta_{m 2} M^{2}+\boldsymbol{\beta}_{z}{ }^{\prime} \boldsymbol{Z}+u
$$

The question of interest is whether the coefficient estimate $\beta_{m}$ becomes robust when a squared term is included (a secondary question is whether $\beta_{m 2}$ is itself robust). Allowing for the inclusion of a squared term, three of these variables become robust: the ratio of total government expenditure to GDP, the share of central-government individual income tax revenue to GDP, and the ratio of total trade to GDP. In addition, the squared terms for two of these variables are also robust. Results for the (robust) linear terms are presented in Panel A of Table 1.

Two of the variables that become robust are indicators of fiscal policy, and indicators of government expenditure and income taxes are both negatively correlated with growth over low values of expenditure and taxes, respectively. The positive squared term in both cases suggests that this correlation attenuates at higher values of the variables. The third robust variable is trade volume, which is robustly negatively correlated with growth at low levels of trade volume, but the estimate of the marginal effect is statistically significant and positive at high values of trade volume.

\section{II.B. Interaction Terms}

A second possibility is that the partial effect of a variable on growth varies over different levels of development. For example, the marginal effect of economic uncertainty on growth 
could be quite different in Germany than in Mexico. One means of capturing such nonlinearities is to include an interaction term between the variable of interest and the country's level of development (proxied for here by initial GDP per capita) in the regression specification. Thus, I repeat the L-R procedure by estimating the following specification:

$$
Y=\beta_{m} M+\beta_{m 2} M \times Y_{0}+\boldsymbol{\beta}_{z}{ }^{\prime} \boldsymbol{Z}+u
$$

where $Y_{0}$ measures initial GDP. The key question is whether $\beta_{m}$ becomes robust when the interaction term is included. In fact, four additional variables become robust: the ratio of total government expenditure to GDP, the ratio of government educational expenditure to GDP, the ratio of central-government tax revenue to GDP, and the share of central-government individual income tax revenue to GDP. Panel B of Table 1 presents results from the L-R procedure for these variables.

Interestingly, all four of the variables that become robust when interaction terms are included are indicators of fiscal policy, and the range of GDP over which each marginal effect is statistically significant is large, covering more than two-thirds of the sample in each case. Combined with the results of the previous section, this suggests some important nonlinearities in the correlations between fiscal policy and growth. ${ }^{4}$ The coefficient estimates are of the traditionally hypothesized sign with indicators of both government expenditure and taxes negatively correlated with growth. However, the positive interaction terms indicate that fiscal policy has less of an effect at higher levels of development.

\section{II.C. Multiple Growth Regimes}

The final nonlinearity considered is the possibility of multiple growth regimes. The theoretical growth literature has documented how, in the presence of sizable spillovers, multiple 
steady states and thus multiple growth regimes can emerge (e.g., see Costas Azariadis and Allan Drazen (1990)).

I divide the full sample into subgroups based on initial income $\left(Y_{0}\right)$, which seems to be the most likely “split” variable for determining multiple regimes (the primary theoretical justification for multiple regimes based on initial development is Azariadas and Drazen (1990); Durlauf and Johnson (1995), Jenny A. Minier (1998), Zhenjuan Liu and Thanasis Stengos (1999), among others, provide empirical justification). Thus, I estimate regressions of the form:

$$
Y=\beta_{m k} M+\boldsymbol{\beta}_{z k} \boldsymbol{Z}+u_{k}
$$

where $k=1$ if $Y_{0}<\underline{Y}$ and $k=2$ otherwise. Since theory does not identify the appropriate subgroups, I arbitrarily divide the sample at two points based on initial income: the 25th and 75th percentiles. Despite the smaller sample sizes, each split results in a substantially higher number of robust variables. Panel $\mathrm{C}$ of Table 1 provides the results for the lowest 75 percent of the sample by income.

Five variables that are not robust in the full sample become robust for the lowest $75 \%$ of countries by income: the ratio of central-government surplus/deficit to GDP, the ratio of government educational expenditure to GDP, the ratio of total government expenditure to GDP, the ratio of central-government tax revenue to GDP, and the standard deviation of domestic credit growth. ${ }^{5}$ Of special interest is that four of these variables are indicators of fiscal policy. Thus, these results indicate that, while fiscal policy indicators might not be robust in the full sample, they are robust in a subsample of lower-income countries. These results are consistent with those of the previous section, in that the marginal effects of fiscal policy appear to be more strongly correlated with growth in low-income countries. Additionally, as in the previous sections, the coefficient estimates are consistent with the standard hypotheses in which indicators 
of government expenditure and indicators of taxes are negatively correlated with growth. In addition, the size of the government surplus is robustly and positively correlated with growth.

The fifth variable that becomes robust in the low-income subsample is the standard deviation of the growth rate of domestic credit, which is a standard indicator of economic variability or uncertainty, and the coefficient estimate is of the hypothesized sign: greater uncertainty is expected to be correlated with lower growth. The fact that this variable is only robust in the low-income subsample is also consistent with the intuitively plausible story that low-income countries are more sensitive to economic uncertainty than high-income countries.

\section{Conclusion}

A major concern with the empirical growth literature has been the sensitivity of the results to the choice of conditioning variables. This fragility may be at least partly due to the common assumption of linearity in growth regressions; when I generalize the specification of the growth regression to allow the marginal effect of explanatory variables to vary, the number of robust variables increases substantially.

The most striking result of the paper is the robustness of fiscal policy variables when one controls for nonlinearities. The correlation between measures of fiscal policy and growth has been of primary concern to many researchers, dating back to the earliest cross-country studies (e.g., Roger Kormendi and Phillip Meguire (1985)). However, one of the primary conclusions of Levine and Renelt (1992) is that none of the fiscal indicators is robustly correlated with growth. In contrast, I find that a broad array of fiscal policy indicators (measuring government expenditure, government taxes and budget deficits) are robustly correlated with growth when potential nonlinearities are taken into account. 
Table 1: Robust Results

\section{Lower Bound $\quad$ Upper Bound}

\section{Panel A: Squared Terms}

\begin{tabular}{llc} 
Expenditure & $-19.8(5.81)$ & $-13.0(6.24)$ \\
Income taxes & $-75.6(22.8)$ & $-46.8(22.5)$ \\
Total trade & $-5.52(1.84)$ & $-3.75(1.52)$ \\
\hline
\end{tabular}

\section{Panel B: Interaction Terms}

\begin{tabular}{lcc} 
Expenditure & $-11.0(2.81)$ & $-7.39(3.05)$ \\
Education expenditures & $-72.7(19.3)$ & $-55.1(20.5)$ \\
Total taxes & $-20.7(4.53)$ & $-12.3(5.22)$ \\
Income taxes & $-56.5(16.9)$ & $-33.3(16.7)$ \\
\hline Panel C: Multiple Regimes (lowest $75 \%$ of GDP) & \\
Expenditure & $-10.7(2.95)$ & $-7.22(2.80)$ \\
Deficit/surplus & $22.5(6.87)$ & $26.6(7.10)$ \\
Education expenditures & $-57.8(18.2)$ & $-40.9(21.0)$ \\
Total taxes & $-19.1(5.11)$ & $-11.2(5.39)$ \\
Std dev of credit growth & $-0.01(0.003)$ & $-0.01(0.002)$ \\
\hline \hline
\end{tabular}

Notes: Results are the coefficient estimate (and standard error) on each variable listed from the growth regression at each bound generated by the robustness procedure described in the text. Only results with both bounds statistically significant at 95 percent or better are presented. 


\section{References}

Azariadis, Costas, and Allan Drazen. 1990. “Threshold Externalities in Economic

Development.” Quarterly Journal of Economics, 105(2): 465-90.

Doppelhofer, Gernot, Ronald I. Miller, and Xavier X. Sala-i-Martin. 2004. "Determinants of

Long-Term Growth: A Bayesian Averaging of Classical Estimates (BACE) Approach.”

American Economic Review, 94(4): 813-35.

Durlauf, Steven N., and Paul A. Johnson. 1995. “Multiple Regimes and Cross-Country Growth

Behaviour.” Journal of Applied Econometrics, 10(4): 365-84.

Kalaitzidakis, Pantelis, Theofanis P. Mamuneas, and Thanasis Stengos. 2000. “A Non-linear

Sensitivity Analysis of Cross-Country Growth Regressions.” Canadian Journal of Economics 33(3): 604-17.

Kormendi, Roger and Phillip Meguire. (1985). “Macroeconomic Determinants of Growth:

Cross-Country Evidence.” Journal of Monetary Economics 16: 141-63.

Leamer, Edward E. 1983. “Let’s Take the Con out of Econometrics.” American Economic

Review 73: 31-43.

Levine, Ross, and David Renelt. 1992. “A Sensitivity Analysis of Cross-Country Growth Regressions.” American Economic Review, 82(4): 942-63.

Liu, Zhenjuan and Thanasis Stengos. 1999. “Non-linearities in Cross-Country Growth

Regressions: A Semiparametric Approach.” Journal of Applied Econometrics, 14(4); 527-38.

Minier, Jenny A. 1998. “Democracy and Growth: Alternative Approaches.” Journal of Economic

Growth, 3(3): 241-66.

Sala-i-Martin, Xavier X. 1997. “I Just Ran Two Million Regressions.” American Economic

Review Papers and Proceedings, 87(2): 178-83. 


\section{Footnotes}

* Department of Economics, University of Kentucky, 335 Gatton College of Business \& Economics, Lexington KY, 40506-0034. E-mail: jminier@uky.edu. I am grateful to Chris Bollinger, Josh Ederington, Brian Krauth, Chris Papageorgiou, Andreas Savvides, and Ken Troske for their comments on an earlier draft. Any errors are, of course, my own.

${ }^{1}$ Investment, schooling, and initial GDP are the only variables confirmed as being robustly correlated with growth in L-R.

${ }^{2}$ I do not allow for nonlinearities in the three variables found to be robust by L-R: investment, initial GDP, and secondary school enrollment.

${ }^{3}$ In contrast, Pantelis Kalaitzidakis, Theofanis P. Mamuneas and Thanasis Stengos (2000) treat the variables of interest as entering the regression linearly, but allow for nonlinearities in the control variables.

${ }^{4}$ Note that government expenditure and taxes are robust when either squared terms or interaction terms are included: this reflects the high positive correlation between GDP per capita and expenditures/taxes. When the linear term, squared term, and interaction term are all included, the interaction term remains statistically significant while the squared term is not, in both cases.

${ }^{5}$ In the highest 75th percentile by income, three fiscal policy variables are robust: government consumption, less defense and education, as share of GDP, the ratio of centralgovernment corporate-income-tax revenue to GDP, and the ratio of central-government tax revenue to GDP. 